\title{
K-12 students' online learning motivation in China: An integrated model based on community of inquiry and technology acceptance theory
}

\author{
Mingzhang Zuo ${ }^{1} \cdot$ Yue Hu${ }^{1}\left(1 \cdot\right.$ Heng Luo $^{1} \cdot$ Hongjie Ouyang ${ }^{1} \cdot$ Yao Zhang $^{1}$
}

Received: 5 July 2021 / Accepted: 18 October 2021 /Published online: 9 November 2021

(C) The Author(s), under exclusive licence to Springer Science+Business Media, LLC, part of Springer Nature 2021

\begin{abstract}
Learning motivation is crucial to online learning success, especially for K-12 students. Although previous research has proved that there are many factors influencing online learning motivation, few studies have systematically investigated this phenomenon from the integrated perspectives of community of inquiry and technology acceptance, two theoretical frameworks that are commonly used to explain experiences of and attitude towards online learning. This study investigates the effects of K-12 students' perceived presence and technology acceptance on their online learning motivation. A total of 13,610 valid questionnaires were collected from K-12 students from Wuhan and adjacent areas in central China participated in the survey. The findings reveal that: (1) perceived usefulness, self-efficacy, social presence, and perceived ease of use have a larger positive effect on online learning motivation, while cognitive presence has a small positive effect on online learning motivation; (2) teaching presence positively influences online learning motivation through social or cognitive presence; (3) factors, such as school location, previous online learning experience, family social-economic status, and prior academic achievements, may influence technology acceptance. The implications for designing, developing, and managing K-12 online education are discussed.
\end{abstract}

Keywords Online learning motivation $\cdot$ Students' perceived presence $\cdot$ Technology acceptance $\cdot$ Self-efficacy

Yue $\mathrm{Hu}$

yuehu@mails.ccnu.edu.cn

1 Faculty of Artificial Intelligence in Education, Central China Normal University, No.152,

LuoYu Street, HongShan District, Wuhan 430079, Hubei, China 


\section{Introduction ${ }^{1}$}

The massive school closures during COVID-19 have forced many students to participate in online learning for the first time (UNESCO, 2020), which is likely to have a lasting impact on education with online learning being an essential component of instructional practice in the post-COVID era (Lockee, 2021). However, online learning is known to suffer from problems such as didactic pedagogy, social isolation, learner procrastination, and technological distraction (Broadbent, 2017; Margaryan et al., 2015; Rasheed et al., 2020), which leads to increased learner dissatisfaction and drop-out rate (O’Neill \& Sai, 2014; Pursel et al., 2016). The sudden transition to online learning mode during COVID-19 outbreak exacerbated the problems with additional challenges such as technology insufficiency, a sense of alienation and COVID-19 anxiety (Toader et al., 2021).

Motivation is critical to the sustainable success of online learning. By energizing, directing, and sustaining students' behavior, online learning motivation (OLM) can foster positivity to continue the online learning process, yielding a strong correlation with online course retention (Charo et al., 2020; Pursel et al., 2016). Therefore, it is particularly important to investigate the factors that influence online learning motivation. Understanding the challenges associated with online learning motivation can enable a better understanding of the inadequacies of online learning practice, which would be particularly important in the post-pandemic world with online learning emerging as a new norm of instruction. Moreover, investigating the factors that affect online learning motivation is especially valuable for K-12 students due to their insufficient online learning skills and experiences. However, most research on online learning motivation is limited to adult learners, and K-12 students as potential beneficiaries of online learning have not been considered.

Research on online learning has established many factors that potentially affect students' online learning motivation (Baker, 2010; Law et al., 2019; Tseng \& Tsai, 2010; Wang et al., 2013), and these factors can be explained through two theoretical frameworks. The first is community of inquiry (CoI), which implies that educational experience occurs at the intersection of three different types of presence, that is, teaching presence (TP), social presence (SP), and cognitive presence (CP) (Garrison et al., 1999). The second is technology acceptance, which was first proposed by Davis (1985), and comprises core variables such as perceived ease of use (PEU) and perceived usefulness (PU), and is extended by external variables, such as self-efficacy (SE) (Scherer et al., 2019). In this study, the online learning context requires self-efficacy to encompass richer connotations, such as academic and computer efficacy.

Some intertwined structures exist between technology acceptance and CoI (Lemay et al., 2018). For example, CoI offers a convenient instrument to assess students' perceptions of learning experience (Geng et al., 2019), which is influenced by

\footnotetext{
${ }^{1}$ CoICommunity of inquiry.

SEMStructural equation modeling.

AVEAverage variance extracted.
} 
technology readiness. Furthermore, technology acceptance can indirectly influence students' online learning motivation through teaching presence, social presence, and cognitive presence. However, even though technology acceptance is associated with the CoI-presences, the structural relationship within this integrated framework is not clear, and there is a lack of research that offers systematic investigation on their interplay and integrated influences on online learning motivation.

Moreover, studies regarding K-12 students' online learning motivation have been mostly conducted in western countries where K-12 online education is more commonly implemented and accepted. Much fewer investigations were conducted in Asian contexts where online teaching is a novel concept for teachers in many of the developing countries, such as China. The outbreak of COVID-19 has created a rare opportunity for K-12 schools in Asian developing countries to conduct online learning on a large scale. We use this experience to identify potential factors that influence K-12 students' online learning motivation in the context of China and explain how these factors and their interplay affect online learning motivation from the perspective of culture and economy, in addition to education.

\section{Literature review}

\subsection{Learning motivation}

Learning motivation implies the student's confidence, tendency, and interest in accomplishing a task to attain a certain goal, and includes the three aspects: interest, value, and ability (Lin et al., 2020). The motivation theory implies that the level of students' confidence about their ability to accomplish a task properly determines their success (Ryan \& Deci, 2000). Motivation is an important factor that is required for successful online learning (Kyewski \& Krämer, 2018; Tseng et al., 2019). It improves online learning performance by attracting learner attention and engaging students in active learning in the online environment (Horzum et al., 2015). For example, Barba et al. (2016) found that students' online learning motivation can positively affect their online learning interest and performance. As online learning motivation significantly impacts students' learning, we attempt to investigate the factors that impact online learning motivation with the purpose of further improving online learning retention and effectiveness.

\subsection{Community of inquiry}

The CoI framework is widely used in online learning research and pedagogy for enriching students' learning experience (Annand, 2011). The three types of presence in the CoI framework integrally promote social and intellectual interaction among participants and materials and, thereby, ensure fruitful learning outcomes (Garrison, 2007). 


\subsubsection{Teaching presence}

Teaching presence refers to learners' perception of the teacher's online teaching behavior to promote the achievement of learning goals and individual meaningful learning outcomes (Garrison et al., 2010). This is critical for designing and organizing online curriculum, facilitating discourse, and identifying teaching approaches (Law et al., 2019). According to Garrison (2007), the higher the perception of a student regarding teaching presence in online learning, the greater would be the educational value assigned to the instructional process or the curriculum. As established by the expectancy-value theory (Wigfield \& Eccles, 2000), if students believe that online learning is beneficial for their field of study or life, their motivation to participate will be higher. Consequently, teaching presence has a positive influence on students' online learning motivation (Cole et al., 2017). Furthermore, it brings social presence and cognitive presence together effectively in the CoI framework (Garrison, 2007). To examine the impact of teaching presence in a K-12 online learning environment, the following hypotheses are proposed:

H1: Teaching presence has a positive impact on online learning motivation.

$\mathrm{H} 2$ : Teaching presence has a positive impact on social presence.

H3: Teaching presence has a positive impact on cognitive presence.

\subsubsection{Social presence}

Social presence refers to the ability of students to communicate purposefully in a trusted environment and the ability to develop interpersonal relationships while protecting their individual personality (Garrison et al., 2010). In a K-12 online environment, students who are used to traditional classrooms may feel lonely or isolated (Doo \& Bonk, 2020), and this may lead to distrust. Online interaction between students and classmates may assist in recalling the familiarity and intimacy with classmates and would increase trust. However, students may feel alienated even though they participate in online classes by video. The anonymity in the online environment allows students to feel safe and comfortable. However, a passive attitude toward online learning may develop if the student is not actively involved in the interaction (Ehrenberg et al., 2001). Thus, the establishment of social presence could be considered as an important factor to enhance online learning motivation. Additionally, students' social presence is also found to have an impact on their cognitive presence, which is indicated by the large path coefficients between the two constructs (Garrison et al., 2010). Therefore, the following hypotheses are proposed in this study:

H4: Social presence has a positive impact on online learning motivation.

H5: Social presence has a positive impact on cognitive presence.

\subsubsection{Cognitive presence}

Cognitive presence is defined as the ability of learners to build a cognitive level of meaning through continuous communication during the online learning process 
(Garrison et al., 2010). When the online learning content is novel and the learning task is challenging, it can stimulate the students' curiosity and promote exploration, analysis, and comparison (Garrison et al., 2010). This is an active methodology of learning which increases a students' initiative, and students with a strong initiative may display higher online learning motivation (Candy, 1991). Additionally, this process was found to strengthen students' higher-order thinking and skill development (Hu et al., 2016). Thus, it is believed that cognitive presence may have a positive influence on students' online learning motivation, and the following hypothesis is proposed:

H6: Cognitive presence has a positive impact on online learning motivation.

\subsection{Technology acceptance}

Technology acceptance refers to the students' behavior regarding the adoption of internet learning (Holden \& Karsh, 2010), by considering the impact of certain beliefs (i.e., perceived ease of use, perceived usefulness, and self-efficacy) on their attitude toward using technology.

\subsubsection{Perceived ease of use}

Perceived ease of use implies the effort that would be required by students to use the online learning platform (Davis, 1985). In the online learning context, if students require a lot of time and effort to familiarize themselves with a learning platform, it may seem like a daunting task to them and will have a negative impact on their intention to use it (Mtebe \& Raisamo, 2014). Consequently, their online learning motivation may also weaken (Tick, 2019). Furthermore, the technology problems are found to be the leading cause of online learning dissatisfaction and discontinuation (Granitz \& Greene, 2003; Peltier et al., 2007). For example, if there are any malfunctions due to incorrect operation, it would severely disrupt the online learning process and would thus negatively affect the students' teaching presence, social presence, and cognitive presence. Thus, the following hypotheses are proposed:

H7: Perceived ease of use has a positive impact on online learning motivation.

H8: Perceived ease of use has a positive impact on teaching presence.

H9: Perceived ease of use has a positive impact on social presence.

H10: Perceived ease of use has a positive impact on cognitive presence.

\subsubsection{Perceived usefulness}

Perceived usefulness refers to the students' perceived value that an online learning platform can enhance their performance, which is consistent with the value dimension of learning motivation (Lin et al., 2020). Specifically, if a student believes that an online learning platform can make learning convenient and efficient, they will be more willing to participate in the learning process. For example, Mada and 
Anharudin (2019) found that an improvement in online motivation was observed in over $80 \%$ of the students if they believed in the effectiveness of "Kahoot," a game-based digital learning platform. During COVID-19 pandemic, various online instructional activities that cultivate teaching presence, social presence, and cognitive presence require the use of online learning platforms, therefore their perceived usefulness may also affect these three types of presence. Thus, the following hypotheses are proposed:

H11: Perceived usefulness has a positive impact on online learning motivation.

H12: Perceived usefulness has a positive impact on teaching presence.

H13: Perceived usefulness has a positive impact on social presence.

H14: Perceived usefulness has a positive impact on cognitive presence.

\subsubsection{Self-efficacy}

Self-efficacy refers to people's judgments of their capabilities to organize and execute a course of action required to attain designated types of performances (Bandura, 1986). An online learning environment gives the concept of self-efficacy a richer connotation, as it communicates the belief that students can easily use online learning platforms. This is a fundamental requirement and it can affect the learning belief which may influence students' choices of learning goals, goal persistence, goal revision, and goal-striving behavior (Bandura, 1997). Through these goal processes, self-efficacy positively influences the motivational elements such as direction, effort, and persistence (Vancouver \& Kendall, 2006), and thus results in stronger online learning motivation among students (Chang et al., 2014). Furthermore, a higherlevel of self-efficacy has been found to be associated with greater engagement in instructional activities, more frequent social communication and discourse, and an increased tendency for active exploration and knowledge construction. It can therefore, promote teaching presence, social presence, and cognitive presence during online learning (Law et al., 2010). Thus, the following hypotheses are proposed:

H15: Self-efficacy has a positive impact on online learning motivation.

H16: Self-efficacy has a positive impact on teaching presence.

H17: Self-efficacy has a positive impact on social presence.

H18: Self-efficacy has a positive impact on cognitive presence.

\section{Methods}

\subsection{Proposed model}

Existing literature highlights the complex nature of online learning and establishes that the perception of learning experience and technology are two closely intertwined concepts. Our semi-structured interviews with students $(n=5)$, teachers $(n=5)$, and parents $(n=3)$ also revealed qualitative evidence that supports the close relationship among online learning motivation, perceived experiences, and 


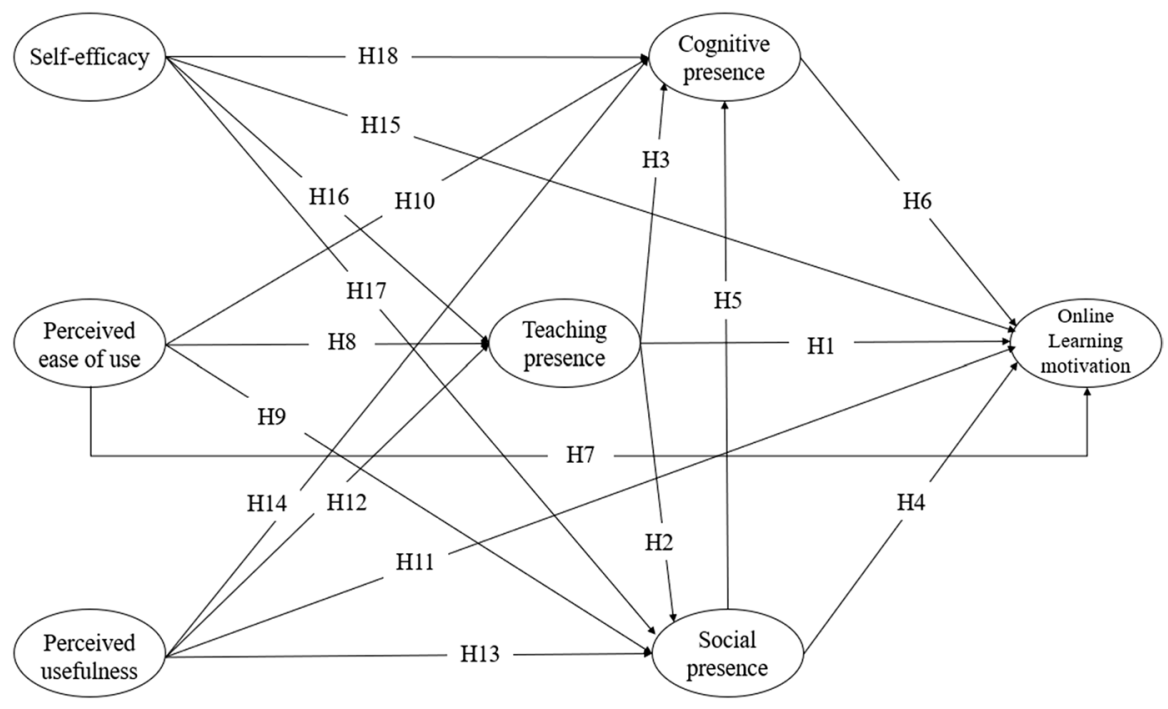

Fig. 1 Research model

technology usage. Therefore, it is necessary to integrate key constructs from technology acceptance and $\mathrm{CoI}$ into one theoretical framework for effectively predicting learning motivation in online learning contexts. Consequently, this study proposes the following model to investigate K-12 students' online learning motivation based on the theory of CoI and technology acceptance (Fig. 1). Structural equation modeling (SEM) was conducted to empirically validate this model.

\subsection{Context of the study and participants}

The sampling population for the present survey research were from the city of Wuhan and its adjacent areas in central China. Because COVID-19 was first reported in Wuhan, so its schools have been most directly affected by the pandemic, and thus have participated in online learning for the longest time period, about 3 months. A total of $18,353 \mathrm{~K}-12$ students participated in the study, who came from 36 urban schools located in urban areas as well as 15 rural schools located in outskirt areas. Due to China's urban migration process since 1990s, urban schools tended to be much larger than outskirt schools with greater student enrollment, whereas the latter are mostly elementary schools providing services to local rural families. As a result, the outskirt schools were purposefully selected in this study to boost the diversity of student social-economic status. These schools were contacted through local education bureaus and participated in the survey voluntarily.

This questionnaire explored family social-economic status and prior academic achievement as important factors affecting learning motivation, and the two parts of data is based on self-report in this study. The reason is that students don't know their household income and grades ranking. Moreover, we believe that family income and grades are sensitive and private information, and direct inquiries would make 
parents or students of low social-economic status feel uncomfortable. Additionally, the literature suggests that the actual income is only partially related to perceived family social-economic status (Goodman et al., 2007), yet the latter is more critical in predicting people's behaviors and perceptions in social events (Ackerman \& Paolucci, 1983).

To ensure the credibility of study results, we conducted an additional procedure to remove invalid answers from survey data. Survey responses that were submitted under 4 min or comprised identical ratings (e.g., selecting A for all items) were identified as invalid answers due to lack of serious consideration, and were excluded from further analysis. In the end, a total of 13,610 valid responses were selected (valid rate: $74.15 \%$ ), and their demographic details were shown in Table 1.

\subsection{Instrument}

In this study, the research instrument includes a questionnaire and a semi-structured interview protocol. The questionnaire was in Chinese and got distributed electronically through a web link during the last week of May 2020 when students were preparing to resume attending school after a 3-month online learning period. At this time, students still had a fresh memory of their online learning experience, and parents can facilitate younger students (e.g., Grade1- Grade3) complete the questionnaire. The questionnaire was anonymous and voluntary, as only the students who were willing to participate would complete and submit their responses. Both teachers and researchers can backtrack individual students regarding the status of completion. The content of the questionnaire and the research protocol were inspected and endorsed by Central China Normal University and local education bureaus.

The questionnaire consisted of two sections. The first comprised 6 single-answer questions about students' demographic information. The second section includes questions about teaching presence, social presence, cognitive presence, perceived ease of use, perceived usefulness, self-efficacy, and online learning motivation based on a 5-point Likert scale ( $1=$ completely disagree, $5=$ completely agree). Among these, the items measuring the CoI-presences were adapted from the instrument validated by Garrison et al. (2010), the items measuring student perceived ease of use and perceived usefulness were informed by Lee (2008), the items measuring student self-efficacy were adapted from Schwarzer (1993) and the items measuring student online learning motivation were informed by Lin et al. (2020). The expression of a few questionnaire items was slightly modified to ensure comprehension for younger students.

The semi-structured interview protocol asked students about their online learning experience, such as encountered problems, perceived effect, use of the platform, perceived three presences, and online learning attitude. Example statements are "How do you think of the effect of your online learning?" and "Have you encountered any problems in online learning?". Additionally, we interviewed a few teachers and parents about how they help and support students to gain a more complete understanding of online learning. 
Table 1 Detailed breakdown of demographic information

\begin{tabular}{llc}
\hline Variable & Category & $\begin{array}{c}\% \text { of } \\
\text { respondents } \\
(\mathrm{N}=13,610)\end{array}$ \\
\hline Gender & & 48.95 \\
Grade level & Male & 51.05 \\
& Female & 46.48 \\
School location & Primary & 37.26 \\
& Middle & 16.24 \\
Previous online learning experience & High & 20.15 \\
& Outskirt & 79.85 \\
& Urban & 37.78 \\
& Never & 23.64 \\
Family social-economic status self-reported & Seldom & 22.38 \\
& Sometimes & 3.38 \\
Prior academic achievement & Often & 12.82 \\
& Always & 7.8 \\
& Poor & 86.6 \\
& Average & 5.6 \\
& Rich & 19.22 \\
& Poor & 37.47 \\
& Middle & 32.87 \\
& Good & 10.44 \\
\hline
\end{tabular}

Confirmatory factor analysis (CFA) was performed to examine the reliability and validity of the questionnaire, and results can be seen in Table 2. Cronbach's alpha values for all constructs are larger than 0.9, suggesting good reliability. Item loadings for all constructs range from 0.67 to 0.94 , indicating good content validity (Doo \& Bonk, 2020). The minimum value of average variance extracted (AVE) for all items is 0.65 , and the composite reliability ranges from 0.91 to 0.95 . This implies that the measurement model has good convergence validity (Gefen et al., 2000). Discriminant validity requires that $\sqrt{\mathrm{AVE}}$ be greater than the correlation coefficient between constructs. In this study, all correlation coefficients are less than $\sqrt{\mathrm{AVE}}$ (Table 3), and therefore, the measurement model has good discriminant validity.

\subsection{Data analysis}

As the CoI questionnaire has thus far, always been applied to online learning for adults, a confirmatory factor analysis was performed to ensure suitability. After the analysis, inappropriate items of teaching presence, cognitive presence, and social presence, were adjusted or deleted. Subsequently, a model was established to analyze the influence factors. SPSS 23 program was used to calculate descriptive, related, and difference analysis. AMOS 18 program was used to test the proposed 
Table 2 Structure of questionnaire and its reliability and validity

\begin{tabular}{lllllll}
\hline Constructs & $\begin{array}{l}\text { Number of } \\
\text { items }\end{array}$ & Mean & Cronbach's alpha & Factor loading & CR & AVE \\
\hline TP & 8 & 4.25 & 0.95 & $0.71-0.91$ & 0.95 & 0.94 \\
SP & 7 & 3.88 & 0.93 & $0.73-0.88$ & 0.93 & 0.92 \\
CP & 7 & 3.77 & 0.94 & $0.77-0.87$ & 0.94 & 0.88 \\
PEU & 3 & 3.60 & 0.91 & $0.85-0.90$ & 0.91 & 0.83 \\
PU & 3 & 3.93 & 0.95 & $0.91-0.94$ & 0.95 & 0.94 \\
SE & 6 & 3.60 & 0.93 & $0.78-0.88$ & 0.93 & 0.92 \\
OLM & 8 & 3.63 & 0.94 & $0.67-0.85$ & 0.94 & 0.94 \\
\hline
\end{tabular}

Table 3 Two-tailed correlations among all Constructs

\begin{tabular}{llllllll}
\hline Constructs & TP & SP & CP & PEU & PU & SE & OLM \\
\hline TP & $\mathbf{0 . 9 7}$ & & & & & & \\
SP & 0.61 & $\mathbf{0 . 9 6}$ & & & & & \\
CP & 0.66 & 0.67 & $\mathbf{0 . 9 7}$ & & & & \\
PEU & 0.52 & 0.76 & 0.66 & $\mathbf{0 . 9 5}$ & & & \\
PU & 0.49 & 0.62 & 0.67 & 0.65 & $\mathbf{0 . 9 7}$ & & \\
SE & 0.46 & 0.67 & 0.66 & 0.55 & 0.59 & $\mathbf{0 . 9 6}$ & \\
OLM & 0.54 & 0.76 & 0.77 & 0.78 & 0.69 & 0.72 & $\mathbf{0 . 9 7}$ \\
\hline
\end{tabular}

The boldface figures in the diagonal represent the square root of AVE figures.

structural model. Finally, we analyzed the interview data qualitatively for triangulation and meaning making of the statistical results.

\section{Results}

\subsection{Structural model assessment and hypotheses testing}

To test the hypotheses, the statistical significance of the path coefficients among the latent variables was examined (Fig. 1). The hypothesized model indicated a good fit to the data $\left(\chi^{2}=24,821.9 ; d f=798 ; \mathrm{GFI}=0.91 ; \mathrm{AGFI}=0.90 ; \mathrm{NFI}=0.95 \mathrm{TLI}=0.95\right.$; $\mathrm{CFI}=0.96$; RMSEA $=0.047$ ). The research findings indicate that all hypotheses were accepted except $\mathrm{H} 1$, which examined the effects of teaching presence on online learning motivation. The result of hypotheses testing is illustrated in Fig. 2.

Perceived usefulness has the greatest impact on online learning motivation $(\beta=0.361)$. This implies that the recognized value of online learning platforms is more likely to affect K-12 students' online learning motivation during the online learning process. Contrarily, perceived ease of use has a rather small direct effect on online learning motivation $(\beta=0.118)$. Furthermore, while it positively influences teaching presence $(\beta=0.308)$ and social presence $(\beta=0.219)$, the influence on cognitive presence is negligeable $(\beta=0.026)$. 


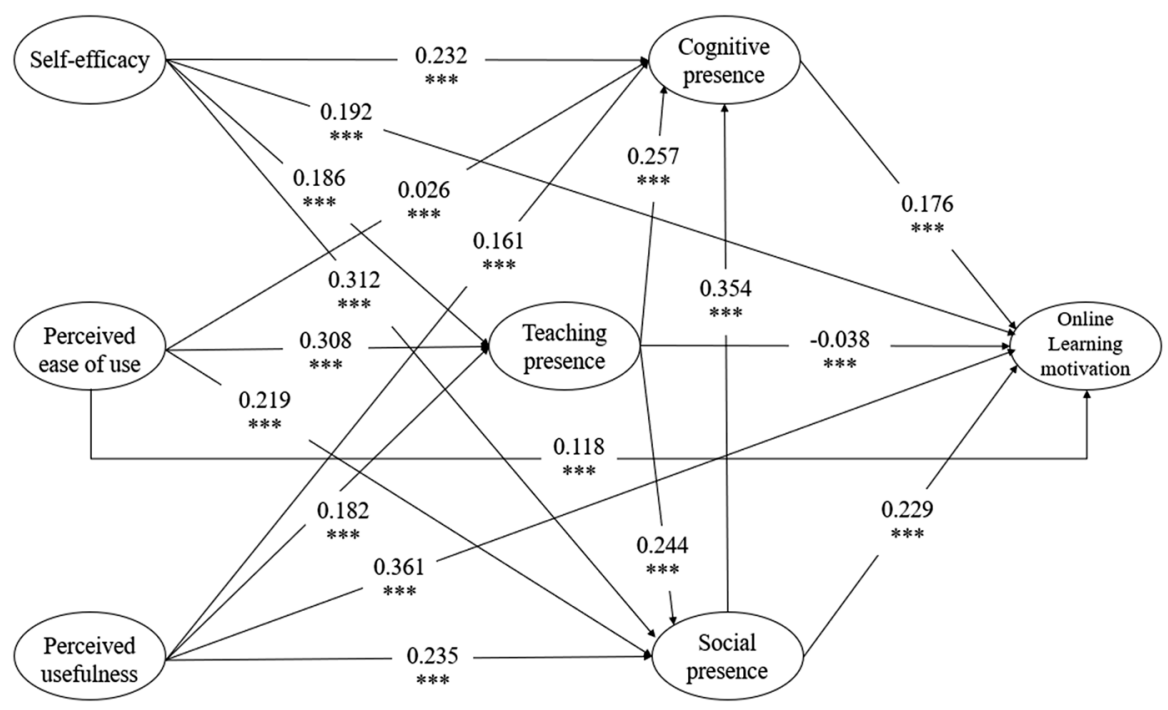

Fig. 2 Results of hypothesis testing

The second most important factor that has a substantial impact on online learning motivation is social presence $(\beta=0.229)$. The direct effect of this factor on online learning motivation is larger than the direct effect of teaching presence $(\beta=-0.038)$ and cognitive presence $(\beta=0.176)$, combined. Interestingly, teaching presence has a small but negative direct effect on online learning motivation $(\beta=-0.038)$, even though it positively influences online learning motivation through indirect effects $(\beta=0.116)$.

Self-efficacy is the third most important factor that has an impact on online learning motivation $(\beta=0.192)$. This finding is not unexpected as perceived competence is defined by the self-determination theory as a positive aspect of intrinsic motivation. Furthermore, self-efficacy has been found to have positive direct effects on all the three types of presence.

Another notable finding is the intertwined relationship of the three types of presence, indicated by their interrelated direct effects as shown in Fig. 2. Consistent with the findings of Garrison et al. (2010), teaching presence was found to positively influence both social presence $(\beta=0.244)$ and cognitive presence $(\beta=0.257)$, suggesting that well-designed instructions are the basis for active learning and social interaction in the online context. The results also emphasize the importance of social presence on promoting reflective inquiry since it has the greatest direct effect on cognitive presence $(\beta=0.354)$, and this effect is larger than what Garrison et al. (2010) found in their study.

Finally, some indirect effects have also been observed in this study. The four larger indirect effects are as following: perceived ease of use on cognitive presence $(\beta=0.183)$, self-efficacy on cognitive presence $(\beta=0.174)$, perceived usefulness on cognitive presence $(\beta=0.146)$, and self-efficacy on online learning motivation $(\beta=0.146)$, with cognitive presence and online learning motivation at the receiving 
end of these indirect effects. A possible explanation for this is that cognitive presence and online learning motivation are complex and multi-faceted constructs and their connotations are often intertwined or may even overlap other key constructs in the proposed model.

\subsection{The influence of demographic variables on exogenous variables}

In SEM, meaningful interpretation of variable relationships requires an understanding of contextual factors, such as students' demographic variables, which may cause different interpretation through influencing exogenous variables. In this study, the research results reveal that the effects of self-efficacy, perceived ease of use, and perceived usefulness on online learning motivation and CoI-presences are different from the previous studies. One possible reason is that student demographic features in China vary greatly from those in western countries, leading to distinct influence on the exogenous variables such as self-efficacy, perceived ease of use, and perceived usefulness.

As shown in Table 4, previous grades have the greatest impact on self-efficacy $\left(\eta_{p}{ }^{2}=0.044\right)$, and this implies that K-12 students with excellent grades may have higher online learning motivation as they have positive self-efficacy. Prior academic achievement also significantly influences the perceived ease of use $\left(\eta_{p}{ }^{2}=0.015\right)$ and perceived usefulness $\left(\eta_{p}{ }^{2}=0.013\right)$, suggesting that high-performing K-12 students tend to accept and master the operation of the online learning platform more easily.

Additionally, factors including grade level, school location, previous online learning experience, and family social-economic status, all lead to significant differences in the three exogenous variables. Among these, the school location has a greater impact on perceived ease of use $\left(\eta_{p}{ }^{2}=0.024\right)$, indicating that the regional inequity in education is also observed in students' technology skills. Similarly, family social-economic status reveals that students from wealthy families reported higher self-efficacy and a more positive attitude toward online learning platforms. Previous online learning experience reflects students' adaptation to the new online learning environment. As seen in Table 4, K-12 students with richer previous online learning experience tend to have a higher opinion of the usefulness of the online learning platform $\left(\eta_{p}{ }^{2}=0.018\right)$. The impact of gender on students' self-efficacy, perceived ease of use, and perceived usefulness of learning platforms, is minimal.

\section{Discussion and conclusion}

This study contributes to the literature by validating a theoretical model to confirm the relationship between CoI-presences, technology acceptance, and online learning motivation. The results of the study can extend the existing knowledge of online learning motivation and experience, specifically in the context of Eastern culture, and can inform the design and implementation of quality online instruction with sustained learner motivation and satisfactory learning experiences in the post-pandemic era. 
Table 4 Impact of student demographics on the three exogenous variables in the SEM

\begin{tabular}{|c|c|c|c|c|}
\hline & & SE & PEU & PU \\
\hline \multirow[t]{3}{*}{ Gender } & Male & 3.62 & 3.91 & 3.59 \\
\hline & Female & 3.59 & 3.96 & 3.61 \\
\hline & $\eta_{p}^{2}$ & 0.001 & 0.001 & 0.000 \\
\hline \multirow[t]{4}{*}{ Grade level } & Primary & 3.65 & 3.86 & 3.62 \\
\hline & Middle & 3.63 & 4.04 & 3.66 \\
\hline & High school & 3.44 & 3.91 & 3.40 \\
\hline & $\eta_{p}^{2}$ & 0.011 & 0.011 & 0.01 \\
\hline \multirow[t]{3}{*}{ School location } & Outskirt & 3.49 & 3.69 & 3.46 \\
\hline & Urban & 3.64 & 3.99 & 3.63 \\
\hline & $\eta_{p}^{2}$ & 0.007 & 0.024 & 0.006 \\
\hline \multirow[t]{6}{*}{ Previous online learning experience } & Never & 3.53 & 3.83 & 3.47 \\
\hline & Seldom & 3.59 & 3.93 & 3.58 \\
\hline & Sometimes & 3.66 & 3.98 & 3.69 \\
\hline & Often & 3.71 & 4.04 & 3.78 \\
\hline & Always & 3.75 & 4.12 & 3.79 \\
\hline & $\eta_{p}{ }^{2}$ & 0.012 & 0.015 & 0.018 \\
\hline \multirow[t]{4}{*}{ Family social-economic status } & Poor & 3.41 & 3.70 & 3.40 \\
\hline & Average & 3.61 & 3.93 & 3.60 \\
\hline & Rich & 3.89 & 4.25 & 3.87 \\
\hline & $\eta_{p}^{2}$ & 0.015 & 0.017 & 0.009 \\
\hline \multirow[t]{5}{*}{ Prior academic achievement } & Poor & 3.39 & 3.79 & 3.43 \\
\hline & Middle & 3.57 & 3.90 & 3.58 \\
\hline & Good & 3.68 & 3.99 & 3.66 \\
\hline & Excellent & 3.92 & 4.12 & 3.78 \\
\hline & $\eta_{p}^{2}$ & 0.044 & 0.015 & 0.013 \\
\hline
\end{tabular}

\subsection{The three Col presences have varying impacts on online learning motivation}

It has been established that social presence has a greater impact on online learning motivation. This finding is consistent with previous research conducted in western countries (Law et al., 2019; Yang et al., 2006). Consequently, it can be stated that the impact of social presence on motivating online learners is universal, and is unaffected by the contextual influencing factors. The general understanding derived is that learning is a social process and discourse plays a key role in the social process of learning, thereby supporting previous literature (Harasim, 2002; Rogoff, 1990). Regarding the unique features of online learning environment, many teachers asserted that it broke the restraints of time and space and enabled more flexible interaction and communications for K-12 students. Therefore, it is extremely important to understand how students and teachers socially interact with each other during online courses. 
Unlike social presence, it has been found that cognitive presence has a smaller impact on online learning motivation. This could be attributed to the K-12 students' cognitive ability in the online learning environment. Although online learning offers an opportunity for possible critical discourse and a reflective space (Garrison, 2003), K-12 students are more likely to participate in online interactive activities rather than other activities involving exploration, analysis, and synthesis due to limited cognitive ability. This interaction may create conducive conditions for sharing and challenging ideas through social discourse, but it does not directly create cognitive presence or facilitate a deep learning approach (Garrison \& Cleveland-Innes, 2005). As argued by many teachers, due to the limited functions of online platforms to support collaborative inquiry, many teachers would only select simple learning activities for online instruction while reserve more complex ones for the face-to-face instruction in the future.

As compared to social presence and cognitive presence, teaching presence, despite its high rating, had rather limited influence on online learning motivation. One possible explanation for this paradoxical finding is that online instruction tended to be highly organized and structured (Zuo et al., 2021), the standardization of instructional design and process inevitably reduced the variation of perceived teaching presence, and thus diminished its prediction of online learning motivation. Moreover, it was observed that teaching presence has an indirect influence $(\beta=0.116)$ on online learning motivation through social presence and cognitive presence in this study. This could be explained by the fact that teaching presence may have possible overlaps between the other two presences since the integration of the cognitive and social elements is realized through instructional design process (Arbaugh \& Hwang, 2006). Therefore, it is difficult to distinguish the extent to which these presences uniquely predict online learning motivation.

\subsection{Perceived usefulness rather than ease of use greatly influences online learning motivation}

Perceived usefulness of online learning has an outstanding impact on online learning motivation among all factors. Students' attitudes towards the value of online learning are shaped by many factors such as grade level, technology competencies, stakes of learning, and cultural norms (Zuo et al., 2021; Rasheed et al., 2020), which profoundly influence students' online learning motivation. For example, the stereotype of online learning as informal and ineffective was prevalent in China before its "Home Study" initiative: learning autonomously on tablet PCs and mobile phones was unimaginable in the past since the presence of digital devices and the absence of teacher supervision were two major educational concerns of parents. The societal resistance and suspicion of online learning, when projected to students, would undoubtedly affect their motivational beliefs as well. Contrarily, students who recognize the values and benefits of online learning are more likely to persevere and excel in online settings (Alraimi et al., 2015; Hone \& Said, 2016).

Although perceived ease of use has a lesser impact on online learning motivation, it has a greater impact on teaching presence. Complex and confusing functions of 
online learning platforms might intimidate teachers while teaching online, resulting in lessons that are poorly designed and structured. Similarly, difficulty in the operation of online platforms might prevent students from studying the online lessons according to the designed sequence and content, leading to a poor evaluation of teaching quality. Consequently, efforts must be made to reduce the learning curve of the usage of online platforms. For example, training should be provided to both teachers and students before online learning, and guidance regarding platform functions and operations should be accessible in various formats. E-learning companies should further enhance the inductivity of platform functions and operations.

\subsection{The influence of social expectations and family social-economic status should not be overlooked}

As seen in Table 4, high school students from outskirt areas tended to have lower selfefficacy of online learning, indicating the important role of social expectation and family SES in shaping online learning experience. The fact that high school students reported lowest self-efficacy is not surprising. In China's current education system, the College Entrance Exam at the end of high school has been assigned with unique significance for both students, parents, and teachers (Xiang, 2018). The social expectation of succeeding in the exam raised a greater degree of academic pressure and anxiety in high school students, when facing the sudden change of learning routine shortly before the exam. Consequently, the feeling of unease and self-doubt started to cumulate, leading to poor self-efficacy of online learning. As one student confessed, "with college entrance exam fast approaching, I became increasingly anxious during online learning as I felt I studied poorly for the past few months and was not ready for the exam."

A possible reason for the difference in self-efficacy between urban and outskirtarea students is that the imbalance in China's regional economy enables urban students to acquire more educational resources and opportunities through families and local schools. As a result, urban students tend to exhibit stronger learning capacities and technical skills, leading to higher self-efficacy for online learning. As complained by many outskirt-school teachers, compared with their urban counterparts, most parents from outskirt areas were indifferent about their children's learning and incapable of helping their students with homework. The poor online learning performance eventually led to poor self-efficacy for outskirt-school students. Our study reveals that selfefficacy has a direct positive impact on online learning motivation and CoI-presences, therefore, special attention should be paid to high school students from outskirt area.

\subsection{Implications}

There are several implications can be drawn from the study results, regarding selfefficacy, online technology, social presence, and education equity.

First, K-12 instructors should provide outskirt students with additional learning assistance (e.g., instructional scaffolds, tutorials, individual guidance, etc.) to improve their self-efficacy. Additionally, Special attention should be paid to high school students due to their high level of academic anxiety. For example, instructors 
should focus on formative rather than summative evaluation, create a more open and democratic atmosphere, and take advantages of anonymity of online learning to reduce anxiety.

Second, it is essential for learning platform developers to reduce the discomfort caused by technology. In addition, as the students' discomfort may decrease or even disappear with continuous training and use, learning platform developers should not only consider the convenience of the platform, but also the functions ability to change the negative perception of students. The most effective way to achieve this could be by communicating with K-12 instructors and taking their needs into consideration.

Third, while conducting online sessions, instructors should intentionally design and organize social learning activities such as online discussion, bullet comments, and peer assessment to reduce loneliness generated by online learning. Learning platform developers should consider the social functions of the platform to support online interactive activities.

Fourth, education administrators need to realize that online learning may further widen the gap between schools located in urban and outskirt areas and should enhance the ICT infrastructure weak schools in outskirt or rural areas.

\subsection{Limitations}

Several limitations of this study should be considered when interpreting the results and implications.

First, while the sample size was relatively large (i.e., 13,610 students), data was only collated from K-12 schools in Wuhan, China. Thus, the generalizability of the research findings for K-12 schools in China or other countries is limited. However, Wuhan offers a unique point of view as it is the city which reported the earliest outbreak of the epidemic. It would be helpful, therefore, if future studies could replicate the aspects of this study in China or other countries.

Second, this study measured online learning motivation, CoI-presences, selfefficacy, and technology acceptance based on a self-reported questionnaire rather than by measuring the actual learning process and learning outcomes through standardized tests and learning analytics. While such data might be difficult to obtain, it could be more accurate and objective than survey data, and would reveal useful information about learning performance and behaviors. Thus, future research can track K-12 students' learning behavior and performance to analyze factors that influence online learning motivation.

Third, in this study, we relied heavily on quantitative data. Although quantitative research can be quickly conducted for large-scale investigations and to grasp development trends, it is insufficient. In-depth narratives of the actual online learning process might reveal the rationale behind the statistical results and assist in the contextual interpretation of quantitative findings. Therefore, it is recommended that future studies include both, quantitative and qualitative approaches. 


\title{
Appendix 1 Questionnaire
}

Greetings! We cordially invite you to complete an online survey based on your online learning experiences during the suspension of normal semester. The purpose of the survey is to understand online learning in terms of perceived experiences, learner acceptance, and learning motivation. Your participation is completely voluntary. You are free to withdraw from the survey at any time without penalty.

\author{
Basic information \\ 1. Your grade is \\ $\bigcirc$ First grade $\bigcirc$ Second grade $\bigcirc$ Third grade $\bigcirc$ Fourth grade $\bigcirc$ Fifth grade \\ $\bigcirc$ Sixth grade $\bigcirc$ Seventh grade $\bigcirc$ Eighth grade $\bigcirc$ Ninth grade $\bigcirc$ Tenth grade \\ $\bigcirc 11$ th grade $\bigcirc 12$ th grade \\ 2.Your school location is \\ $\bigcirc$ Urban $\bigcirc$ Outskirt \\ 3.Your sex is \\ $\bigcirc$ Male $\bigcirc$ Female \\ 4.Have you participated in online courses in the past? \\ $\bigcirc$ Never $\bigcirc$ Seldom $\bigcirc$ Sometimes $\bigcirc$ Often $\bigcirc$ Always \\ 5 . How would you describe your family in terms of wealth? \\ $\bigcirc$ Poor $\bigcirc$ Average $\bigcirc$ Rich \\ 6 . What is your academic record last semester? \\ $\bigcirc$ Excellent $\bigcirc$ Good $\bigcirc$ Middle $\bigcirc$ Poor
}

Teaching presence

1.The instructor clearly communicated important course goals

2.The instructor provided clear instructions on how to participate in course learning activities

3.The instructor helped keep the course participants on task in a way that helped me to learn

4.The instructor was helpful in identifying areas of agreement and disagreement on course topics that helped me to learn

5.The instructor encouraged course participants to explore new concepts in this course

6.The instructor helped to keep course participants engaged and participating in productive dialogue

7.Instructor actions reinforced the development of a sense of community among course participants

8.The instructor clearly communicated important due dates/time frames for learning activities

Social presence

1.I feel comfortable interacting with other students on the online course

2.I felt comfortable disagreeing with other course participants while still maintaining a sense of trust

3.I felt that my point of view was acknowledged by other course participants

4.Getting to know other course participants gave me a sense of belonging in the course

5.Online or web-based communication is an excellent medium for social interaction

6.Online discussions help me to develop a sense of collaboration

7.I was able to form distinct impressions of some course participants

Cognitive presence

1.I felt motivated to explore content related questions

2.I can apply the knowledge created in this course to my work or other non-class related activities

3.Learning activities helped me construct explanations/solutions

4.Reflection on course content and discussions helped me understand fundamental concepts in this class

5.Online discussions were valuable in helping me appreciate different perspectives

6.I can describe ways to test and apply the knowledge created in this course

7.I utilized a variety of information sources to explore problems posed in this course 
Online learning motivation

1.I think the learning tasks in online learning are very interesting

2.I believe that the activities in online learning are valuable to me

3.I don't feel nervous at all when participating in online learning activities

4.I think participating in online learning activities helps to understand the learning content

5.I think online learning content is very easy to learn

6.I like online learning content very much

7.I am satisfied with my performance in completing online learning tasks

8.I think participating in online learning activities will be beneficial to me

Self-efficacy

1.In online learning, I am confident that I can effectively deal with any sudden events

2.If I put in enough effort, I will be able to solve most of the problems during online learning

3. In online learning, I can face difficulties calmly because I believe in my ability to deal with problems

4.When facing a problem in online learning, I can usually find multiple solutions

5.When encountering a problem in online learning, I can usually think of some solutions

6.No matter what happens in online learning, I can handle it with ease

Perceived usefulness

1.Online learning can make me have a better learning performance

2.Online learning can improve my learning efficiency

3.Online learning is very helpful to my study

Perceived ease of use

1.I think the design of the online learning platform or software is clear and understandable

2.I think the online learning platform or software are easy to use

3.I can easily use online learning platforms or software to carry out learning activities

\section{Appendix 2 Interview protocol}

\section{For students}

1. Can you describe the process of your participation in online learning?

2. What platform do you use for online learning? How do you use platforms for learning?

3. How do you think of the effect of your online learning? (performance, attention, homework, etc.)

4. How is your online learning experience (perceived teaching, social, and cognitive presence)

5. Do you communicate with teachers? Please elaborate

6. Do your parents help you during online learning? Please elaborate

7. Have you encountered any problems in online learning?

8. Will you continue to use online learning in the future?

For teachers

1. Can you describe the process of online teaching in your school?

2. What platform do you use for online teaching? How do you use platforms for online teaching?

3. What do you think of the effect of online teaching? (From the perspective of teaching process)

4. How do students perform in online learning? (Compare with learning in traditional classrooms)

5. How do students communicate with you? Please elaborate

6. How do parents communicate with you? Please elaborate

7. Have you encountered any problems in online teaching? (In terms of teaching implementation, device, etc.) 


\section{For parents}

1. Do you know your children's online learning situation?

2. What have you done for your children's online learning?

3. How effective is your children's online learning?

4. Did your children have any problems with online learning? Please elaborate

5 . How do you help your children solve the problems encountered in online learning?

6. In your opinion, what aspects of online learning need to be further improved in the future?

Acknowledgements This study was funded by the Key Research Project of Education supported by National Social Science Foundation of China (No. ACA170010).

Authors' contributions First author: Conceptualization, Writing - original draft, Funding acquisition, Supervision,

Second author: Writing - original draft and editing, Formal analysis, Investigation, Supervision,

Third author: Writing - revision and editing, Formal analysis,

Fourth author: Investigation, Formal analysis,

Fifth author: Investigation, Formal analysis,

Data Availability Statement The data that support the findings of this study are openly available in Mendeley Data at http://dx.doi.org/10.17632/gjy69zmnk8.3

\section{Declarations}

Conflict of Interest Statement There is no potential conflict of interest, as we conducted this study only because of our research interests.

\section{References}

Zuo, M., Ma, Y., Hu, Y., \& Luo, H. (2021). K-12 students' online learning experiences during COVID19: Lessons from China. Frontiers of Education in China, 16(1), 1-30. https://doi.org/10.1007/ s11516-021-0001-8

Ackerman, N., \& Paolucci, B. (1983). Objective and subjective income adequacy: Their relationship to perceived life quality measures. Social Indicators Research, 12(1), 25-48.

Alraimi, K. M., Zo, H., \& Ciganek, A. P. (2015). Understanding the MOOC continuance: the role of openness and reputation. Computers \& Education, 80(JAN), 28-38. https://doi.org/10.1016/j.compe du.2014.08.006

Arbaugh, J. B., \& Hwang, A. (2006). Does "teaching presence" exist in online MBA courses? The Internet and Higher Education, 9(1), 9-21. https://doi.org/10.1016/j.iheduc.2005.12.001

Annand, D. (2011). Social presence within the community of inquiry framework. International Review of Research in Open and Distributed Learning, 12(5), 40-56. https://doi.org/10.19173/irrodl.v12i5. 924

Baker, C. (2010). The impact of instructor immediacy and presence for online student affective learning, cognition, and motivation. Journal of Educators Online, 7(1), 30. https://doi.org/10.9743/JEO. 2010.1.2

Bandura, A. (1997). Self-efficacy: The exercise of control. Freeman.

Bandura, A. (1986). Social foundations of thought and action: A social cognitive theory. Prentice-Hall.

Barba, P. G., Kennedy, G. E., \& Ainley, M. D. (2016). The role of students' motivation and participation in predicting performance in a MOOC. Journal of Computer Assisted Learning, 32(3), 218-231. https://doi.org/10.1111/jcal.12130

Broadbent, J. (2017). Comparing online and blended learner's self-regulated learning strategies and academic performance. The Internet and Higher Education, 33, 24-32. https://doi.org/10.1016/j.iheduc.2017.01.004

Candy, P. C. (1991). Self-Direction for Lifelong Learning. Jossey-Bass. 
Chang, C., Liu, E. Z., Sung, H., Lin, C., Chen, N., \& Cheng, S. (2014). Effects of online college student's Internet self-efficacy on learning motivation and performance. Innovations in Education and Teaching International, 51(4), 366-377. https://doi.org/10.1080/14703297.2013.771429

Charo, R., Maite, A. S., \& Guillermo, M. (2020). Self-regulation of learning and MOOC retention. Computers in Human Behavior, 111, 106423. https://doi.org/10.1016/j.chb.2020.106423

Cole, A., Anderson, C., Bunton, T., Cherney, M., Fisher, V. C., Featherston, M., Motel, L., Nicolini, K., Peck, B., \& Allen, M. (2017). Student predisposition to instructor feedback and perceptions of teaching presence predict motivation toward online courses. Online Learning Journal, 21(4), 245262. https://doi.org/10.24059/olj.v21i4.966

Davis, F. D. (1985). A technology acceptance model for empirically testing new end-user information systems: Theory and results. Massachusetts Institute of Technology.

Doo, M. Y., \& Bonk, C. J. (2020). The effects of self-efficacy, self-regulation and social presence on learning engagement in a large university class using flipped Learning. Journal of Computer Assisted Learning, 36(6), 997-1010. https://doi.org/10.1111/jcal.12455

Ehrenberg, R. G., Brewer, D. J., Gamoran, A., \& Willms, J. D. (2001). Class size and student achievement. Psychological Science in the Public Interest, 2(1), 1-30. https://doi.org/10.1111/1529-1006. 003

Garrison, D. R. (2003). Cognitive presence for effective asynchronous online learning: The role of reflective inquiry, self-direction, and metacognition. Elements of Quality Online Education: Practice and Direction, 4(1), 47-58.

Garrison, D. R. (2007). Online community of inquiry review: Social, cognitive, and teaching presence issues. Journal of Asynchronous Learning Networks, 11(1), 61-72. https://doi.org/10.24059/olj. v11i1.1737

Garrison, D. R., Anderson, T., \& Archer, W. (1999). Critical inquiry in a text-based environment: Computer conferencing in higher education. The Internet and Higher Education, 2(2-3), 87-105. https:// doi.org/10.1016/S1096-7516(00)00016-6

Garrison, D. R., Cleveland-Innes, M., \& Fung, T. S. (2010). Exploring causal relationships among teaching, cognitive and social presence: Student perceptions of the community of inquiry framework. The Internet and Higher Education, 13(1-2), 31-36. https://doi.org/10.1016/j.iheduc.2009.10.002

Garrison, D. R., \& Cleveland-Innes, M. (2005). Facilitating cognitive presence in online learning: Interaction is not enough. The American Journal of Distance Education, 19(3), 133-148. https://doi.org/ 10.1207/s15389286ajde1903_2

Gefen, D., Straub, D., \& Boudreau, M. (2000). Structural equation modeling and regression: Guidelines for research practice. Communications of the Association for Information Systems, 4(1), 7. https:// doi.org/10.17705/1CAIS.00407

Geng, S., Law, K. M., \& Niu, B. (2019). Investigating self-directed learning and technology readiness in blending learning environment. International Journal of Educational Technology in Higher Education, 16(1), 1-12. https://doi.org/10.1186/s41239-019-0147-0

Goodman, E., Huang, B., Schafer-Kalkhoff, T., \& Adler, N. E. (2007). Perceived socioeconomic status: A new type of identity that influences adolescents' self-rated health. Journal of Adolescent Health, 41(5), 479-487. https://doi.org/10.1016/j.jadohealth.2007.05.020

Granitz, N., \& Greene, C. S. (2003). Applying e-marketing strategies to online distance learning. Journal of Marketing Education, 25(1), 16-30. https://doi.org/10.1177/0273475302250569

Harasim, L. (2002). What makes online learning communities successful: The role of collaborative learning in social and intellectual development. In C. Vrasidas and G. V. Glass (Eds.), Distance education and distributed learning (181-200). Greenwich, CT: Information Age Publishing

Hone, K. S., \& Said, G. R. E. (2016). Exploring the factors affecting MOOC retention: a survey study. Computers \& Education, 98(Mar.), 157-168. https://doi.org/10.1016/j.compedu.2016.03.016

Horzum, M. B., Kaymak, Z. D., \& Gungoren, O. C. (2015). Structural equation modeling towards online learning readiness, academic motivations, and perceived learning. Educational Sciences: Theory \& Practice, 15(3), 759-770. https://doi.org/10.12738/estp.2015.3.2410

Hu, W., Jia, X., Plucker, J. A., \& Shan, X. (2016). Effects of a critical thinking skills program on the learning motivation of primary school students. Roeper Review, 38(2), 70-83. https://doi.org/10. 1080/02783193.2016.1150374

Kyewski, E., \& Krämer, N. C. (2018). To gamify or not to gamify? An experimental field study of the influence of badges on motivation, activity, and performance in an online learning course. Computers \& Education, 118, 25-37. https://doi.org/10.1016/j.compedu.2017.11.006 
Law, K. M. Y., Geng, S., \& Li, T. (2019). Student enrollment, motivation and learning performance in a blended learning environment: The mediating effects of social, teaching, and cognitive presence. Computers and Education, 136, 1-12. https://doi.org/10.1016/j.compedu.2019.02.021

Law, K. M., Lee, V. C., \& Yu, Y. (2010). Learning motivation in e-learning facilitated computer programming courses. Computers \& Education, 55(1), 218-228. https://doi.org/10.1016/j.compedu.2010.01. 007

Lee, Y. (2008). The role of perceived resources in online learning adoption. Computers \& Education, 50(4), 1423-1438. https://doi.org/10.1016/j.compedu.2007.01.001

Lemay, D., Doleck, T., \& Bazelais, P. (2018). The Influence of the Social, Cognitive, and Instructional Dimensions on Technology Acceptance Decisions among College-Level Students. Eurasia Journal of Mathematics, Science and Technology Education, 14(12), 1-11. https://doi.org/10.29333/ejmste/ 97192

Lin, L., Ginns, P., Wang, T., \& Zhang, P. (2020). Using a pedagogical agent to deliver conversational style instruction: What benefits can you obtain? Computers \& Education, 143(1), 1-11. https://doi. org/10.1016/j.compedu.2019.103658

Lockee, B. B. (2021). Online education in the post-covid era. Nature Electronics, 4(1), 5-6.

Mada, R. D., \& Anharudin, A. (2019). How Online Learning Evaluation (Kahoot) Affecting Students' Achievement and Motivation (Case Study on it Students). International Journal for Educational and Vocational Studies, 1(5), 422-427. https://doi.org/10.29103/ijevs.v1i5.1494

Margaryan, A., Bianco, M., \& Littlejohn, A. (2015). Instructional quality of massive open online courses (MOOCS). Computers \& Education, 80, 77-83. https://doi.org/10.1016/j.compedu.2014.08.005

Mtebe, J., \& Raisamo, R. (2014). Investigating students' behavioral intention to adopt and use mobile learning in higher education in East Africa. International Journal of Education and Development using ICT, 10(3),4-20. Retrieved April 15, 2021, from https://www.learntechlib.org/p/148476/

O'neill, D. K., \& Sai, T. H. (2014). Why not? Examining college students' reasons for avoiding an online course. Higher Education, 68(1), 1-14. https://doi.org/10.1007/s10734-013-9663-3

Peltier, J. W., Schibrowsky, J. A., \& Drago, W. (2007). The interdependence of the factors influencing the perceived quality of the online learning experience: A causal model. Journal of Marketing Education, 29(2), 140-153. https://doi.org/10.1177/0273475307302016

Pursel, B. K., Zhang, L., Jablokow, K. W., Choi, G. W., \& Velegol, D. (2016). Understanding MOOC students: Motivations and behaviors indicative of MOOC completion. Journal of Computer Assisted Learning, 32(3), 202-217. https://doi.org/10.1111/jcal.12131

Rasheed, R. A., Kamsin, A., \& Abdullah, N. A. (2020). Challenges in the online component of blended learning: A systematic review. Computers \& Education, 144(1), 103701. https://doi.org/10.1016/j. compedu.2019.103701

Rogoff, B. (1990). Apprenticeship in thinking: Cognitive development in social context. Oxford University Press.

Ryan, R. M., \& Deci, E. L. (2000). Intrinsic and extrinsic motivations: Classic definitions and new directions. Contemporary Educational Psychology, 25(1), 54-67. https://doi.org/10.1006/ceps.1999.1020

Holden, R. J., \& Karsh, B. (2010). The technology acceptance model: It's past and its future in health care. Journal of Biomedical Informatics, 43(1), 159-172. https://doi.org/10.1016/j.jbi.2009.07.002

Scherer, R., Siddiq, F., \& Tondeur, J. (2019). The technology acceptance model (TAM): A meta-analytic structural equation modeling approach to explaining teachers' adoption of digital technology in education. Computers \& Education, 128, 13-35. https://doi.org/10.1016/j.compedu.2018.09.009

Schwarzer, R. (1993). Measurement of perceived self-efficacy: Psychometric scales for cross-cultural research. Freie Universität.

Tick, A. (2019). An Extended TAM Model, for Evaluating eLearning Acceptance, Digital Learning and Smart Tool Usage. Acta Polytechnica Hungarica, 16(9), 213-233.

Toader, T., Safta, M., Titiric, C., \& Firtescu, B. (2021). Effects of digitalisation on higher education in a sustainable development framework-online learning challenges during the COVID-19 pandemic. Sustainability, 13, 6444. https://doi.org/10.3390/su13116444

Tseng, H., Yi, X., \& Yeh, H. (2019). Learning-related soft skills among online business students in higher education: Grade level and managerial role differences in self-regulation, motivation, and social skill. Computers in Human Behavior, 95, 179-186. https://doi.org/10.1016/j.chb.2018.11.035

Tseng, S., \& Tsai, C. (2010). Taiwan college students' self-efficacy and motivation of learning in online peer assessment environments. The Internet and Higher Education, 13(3), 164-169. https://doi.org/ 10.1016/j.iheduc.2010.01.001 
UNESCO. (2020). Global Education Monitoring Report 2020: Inclusion and education: All means all. Paris, UNESCO. Retrieved August 25, 2021, from http://bit.ly/2020gemreport

Vancouver, J. B., \& Kendall, L. N. (2006). When self-efficacy negatively relates to motivation and performance in a learning context. Journal of Applied Psychology, 91(5), 1146-1153. https://doi.org/10. 1037/0021-9010.91.5.1146

Wang, C., Shannon, D. M., \& Ross, M. E. (2013). Students' characteristics, self-regulated learning, technology self-efficacy, and course outcomes in online learning. Distance Education, 34(3), 302-323. https://doi.org/10.1080/01587919.2013.835779

Wigfield, A., \& Eccles, J. S. (2000). Expectancy - value theory of achievement motivation. Contemporary Educational Psychology, 25(1), 68-81. https://doi.org/10.1006/ceps.1999.1015

Xiang, X. (2018). My future, my family, my freedom: meanings of schooling for poor, rural chinese youth. Harvard educational review, 88(1), 81-102. https://doi.org/10.17763/1943-5045-88.1.81

Yang, C. C., Tsai, I. C., Kim, B., Cho, M. H., \& Laffey, J. M. (2006). Exploring the relationships between students' academic motivation and social ability in online learning environments. The Internet and Higher Education, 9(4), 277-286. https://doi.org/10.1016/j.iheduc.2006.08.002

Publisher's Note Springer Nature remains neutral with regard to jurisdictional claims in published maps and institutional affiliations. 